\title{
Profile of Daily Life in Children with Brain Tumors: An Assessment of PedsQL 4.0 Generic Core Scales before and after Treatment
}

\author{
Julius July ${ }^{1,2 *}$, Natasha Bastiaan ${ }^{1}$, Steven Tandean ${ }^{3}$, Michael Lumintang Loe ${ }^{3}$ \\ ${ }^{1}$ Department of Neurosurgery, Faculty of Medical, Universitas Pelita Harapan, Neuroscience Centre of Siloam Hospital, Lippo \\ Village, Tangerang, Indonesia; ${ }^{2}$ Mochtar Riady Institute for Nanotechnology and Medical Science Group, Universitas Pelita \\ Harapan, Lippo Village, Tangerang, Indonesia; ${ }^{3}$ Department of Neurosurgery, Faculty of Medicine, Universitas Sumatera Utara/ \\ Haji Adam Malik General Hospital, Medan 20155, Indonesia
}

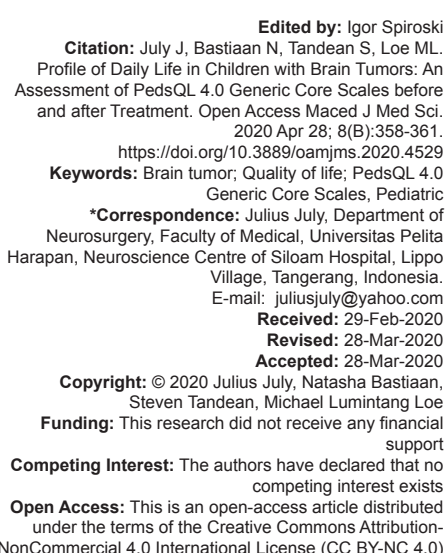

Edited by: Igor Spiroski

Edited by: Igor Spiroski
Citation: July J, Bastiaan N, Tandean S, Loe ML. Citation: July J, Bastiaan N, Tandean S, Loe ML.
Profile of Daily Life in Children with Brain Tumors: An Assessment of PedsQL 4.0 Generic Core Scales before and after Treatment. Open Access Maced J Med Sci. 2020 Apr 28; 8(B):358-361. https://doi.org/10.3889/oamjms.2020.4529 Keywords: Brain tumor; Quality of life; PedsQL 4.0 Generic Core Scales, Pediatric *Correspondence: Julius July, Department of Neurosurgery, Faculty of Medical, Universitas Pelita Harapan, Neuroscience Centre of Siloam Hospital, Lippo Village, Tangerang, Indonesia. Received: 29-Feb-2020 Revised: $28-$ 2 - 2 - 2020 Revised: 28-Mar-2020
Accepted: 28-Mar-2020 Accepted: 28-Mar-2020
Copyright: $\odot 2020$ Julius July, Natasha Bastiaan Copyright:
Steven Tandean, Michael Lumintang Loe Funding: This research did not receive any financia Competing Interest: The authors have declared that no competing interest exist Open Access: This is an open-access article distribute under the terms of the Creative Commons Attribution-

\section{Abstract}

BACKGROUND: Pediatric brain tumors are the most common solid tumor and cause of death among all childhood cancers. In America, brain tumor prevalence is $21.42 / 100.000$ population. Even though survival rate is improving, the impact of treatment for long-term quality of life is still a challenge.

\begin{abstract}
AIM: We aimed to investigate quality of life score using PedsQL 4.0 Generic Core Scales.
\end{abstract}
METHODS: The data collected based on the inclusion criteria from patient's medical records 2015-2017 period on January 2018-May 2018 in Siloam Hospital, Lippo Village, Karawaci. Twenty-six brain tumor pediatric patients with surgical treatment were evaluated using PedsQL 4.0 Generic Core Scales. The evaluation included before and after condition of the patient. PedsQL 4.0 Generic Core Scales were divided into four categories; physical function, emotional function, social function, and school function. They were analyzed statically using Wilcoxon test with $p<$ 0.05 considered as statistically significant.

RESULTS: The result showed that before treatment score of PedsQL 4.0 Generic Core Scales was classified as medium functioning (58.54/92) and after treatment score of PedsQL 4.0 Generic Core Scales was classified as intermediate functioning (37.3/92)

CONCLUSION: The conclusion is that patient after treatment (surgery, chemotherapy, and radiation) shows improved quality of life score using PedsQL 4.0 Generic Core Scales.

\section{Introduction}

Pediatric brain tumor is the most common solid tumor and cause of death among all childhood cancers. The prevalence of pediatric brain tumors at the United States are 21.42/100.000 population with incidence 1500-2000 children's every year. As a result of medical technology development, mortality has been reduced significantly but morbidity also increased [1], [2]. Brain tumor can affect quality of life including physic and psychology of pediatric in daily life activity. Besides that, brain tumor also can influence intellectual, emotional, and academic of pediatrics. Factors that can influence pediatric quality of life are complex including brain tumor itself, family socioeconomy, health-care provider, family education background, interpersonal factor, and culture. Several factors of brain tumor that can affect morbidity are location and extension of tumor, age, and increased intracranial pressure [3], [4].

Nowadays, quality of life measurement has important role in brain tumor treatment in pediatrics.
One of questionnaire that has been widely used is PedsQL 4.0 Generic Core Scales. PedsQL 4.0 Generic Core Scales can be used to measure physic, emotional, social, and academic function of pediatrics. This questionnaire can be filled by self-report or by parent proxy report. PedsQL 4.0 Generic Core Scales contain 8 questions for physic function, 5 questions for emotional emotion, 5 questions for social function, and 5 questions for academic function. Quality of life is also important part of brain tumor treatment in pediatric. As more pediatric brain tumor survive, the need of longterm follow up and monitoring of quality of life continue to need development [5], [6].

\section{Methods}

This research used observational crosssectional design to study the quality of life of pediatric brain tumors survival in Siloam Hospital, Lippo Village, 
Tangerang, Indonesia. All children between two and 18 years old with confirmed primary brain tumor that completed therapy and survived for at least 6 months were included in this study. From 2015 to 2017, there are 43 pediatrics screened but only 26 pediatrics participate the study. Excluded patients were 5 children discontinued treatment, 11 pediatrics were died, and 1 patient refused to participate. Patients quality of life was evaluated with PedsQL 4.0 Generic Core Scales. Questionnaires were answered by patients and their parent through phone calls while patients history from medical records.

Informed consent from all patients and their parents with ethical approval from Ethics Committee of Universitas Pelita Harapan was acquired before the study. Questionnaires will be asked directly to patients if above 9 years old and could communicate well, and aside from that answered from their parents. All 26 patients or their parents have to answered 23 questions PedsQL simultaneous before and after treatment with only three answers, i.e. no problem, sometimes, and big problem. All the collected data will be proceed into four categories, i.e. high functioning (0-24 point), intermediated functioning (26-46 point), medium functioning (48-68 point), and low functioning (70-92 point). This study was analyzed statistically using the SPSS ${ }^{\circledR}$ statistic version 24 (Armonk, NY). Paired t-test was used on normal distribution and Wilcoxon when not normal distributed with confidence interval of $95 \%$.

\section{Results}

Characteristics of patients that followed this study are shown in Table 1. Mean age of this study is 14-18 years old $(35 \%)$. This study was dominant in male $(65 \%)$ but equal in brain tumor type.

Table 1: Patients' characteristics

\begin{tabular}{lll}
\hline Variable & $\mathrm{n}$ & $\%$ \\
\hline Age & 4 & \\
$2-5$ years old & 3 & 15 \\
$6-9$ years old & 6 & 12 \\
$10-13$ years old & 9 & 23 \\
$14-18$ years old & 4 & 35 \\
$\quad>18$ years old & & 15 \\
Sex & 17 & 65 \\
$\quad$ Male & 9 & 35 \\
$\quad$ Female & 13 & 50 \\
Brain tumor type & 13 & 50 \\
$\quad$ Benign & & \\
Malignant & &
\end{tabular}

From 26 patients that participated in this research, 14 questionnaires were answered autoanamnesis while others 12 questionnaires by their parents. PedsQL contains four categories physical (8 questions), emotional (5 questions), social (5 questions), and school function (5 questions). From physical function, before surgery, all questionnaires were answered quite poor $(n=16,62 \%)$ and poor $(n=10$, $38 \%$ ) but after surgery became good $(n=6,23 \%)$, quite good ( $n=7,27 \%)$, quite poor $(n=13,50 \%)$, and none answered poor. From emotional function, before surgery, result was good $(\mathrm{n}=3,11 \%)$, quite good $(\mathrm{n}=$ $16,62 \%)$, quite poor $(n=5,19 \%)$, and poor $(n=2,8 \%)$ but after surgery, result became good ( $n=10,38 \%)$, quite good $(n=10,38 \%)$, quite poor $(n=4,16 \%)$, and poor $(n=2,8 \%)$. From social function, before surgery, result was good $(n=0)$, quite good $(n=9,35 \%)$, quite poor $(n=14,54 \%)$, and poor $(n=3,11 \%)$ but after surgery, result became good ( $n=10,38 \%)$, quite good $(n=12,46 \%)$, quite poor $(n=2,8 \%)$, and poor $(n=2$, $8 \%$ ). From emotional function, before surgery, result was good $(n=3,11 \%)$, quite good $(n=16,62 \%)$, quite poor $(n=5,19 \%)$, and poor $(n=2,8 \%)$ but after surgery, result became good $(n=10,38 \%)$, quite good $(n=10$, $38 \%)$, quite poor $(n=4,16 \%)$, and poor $(n=2,8 \%)$. From school function, before surgery, result was good $(n=0)$, quite good $(n=14,54 \%)$, quite poor $(n=8$, $30 \%)$, and poor ( $n=4,16 \%$ ) but after surgery, result became good $(n=9,35 \%)$, quite good $(n=14,54 \%)$, quite poor $(n=0)$, and poor $(n=3,11 \%)$. From quality of life, before surgery was good $(n=0)$, quite good $(n=4$, $16 \%)$, quite poor $(n=17,65 \%)$, and poor $(n=5,19 \%)$ but after surgery, result became good ( $n=7,27 \%)$, quite good $(n=13,50 \%)$, quite poor $(n=6,23 \%)$, and poor $(n=0)$ (Table 2).

Table 2: Results of PedsQL before and after surgery

\begin{tabular}{|c|c|c|c|c|c|c|c|c|c|c|}
\hline \multirow[t]{2}{*}{ Result } & \multicolumn{5}{|c|}{ Before treatment (\%) } & \multicolumn{5}{|c|}{ After treatment (\%) } \\
\hline & $a$ & $\mathrm{~b}$ & C & d & $\mathrm{e}$ & $a$ & $\mathrm{~b}$ & c & $\mathrm{d}$ & $\mathrm{e}$ \\
\hline Good & $0(0)$ & $3(11)$ & $0(0)$ & $0(0)$ & $0(0)$ & $6(23)$ & $10(38)$ & $10(38)$ & $9(35)$ & $7(27)$ \\
\hline $\begin{array}{l}\text { Quite } \\
\text { good }\end{array}$ & $0(0)$ & $16(62$ & $9(35)$ & $14(54)$ & $4(16)$ & $7(27)$ & $10(38)$ & $12(46)$ & $14(54)$ & $13(50)$ \\
\hline $\begin{array}{l}\text { Quite } \\
\text { poor }\end{array}$ & $16(62)$ & 5 (19) & $14(54)$ & $8(30)$ & $17(65)$ & $13(50)$ & $4(16)$ & $2(8)$ & $0(0)$ & $6(23)$ \\
\hline Poor & $10(38)$ & $2(8)$ & $3(11)$ & $4(16)$ & $5(19)$ & $0(0)$ & $2(8)$ & $2(8)$ & $3(11)$ & $0(0)$ \\
\hline
\end{tabular}

Comparison between before and after surgery result showed improvement in every category except emotional function. Result for quality of life before surgery is quite poor (58.54) and becomes quite good (37.3) after surgery. Result for physic function before surgery is quite poor (23.61) and becomes quite good (15.54) after surgery. Result for social function before surgery is quite poor (12.69) and becomes quite good (7.38) after surgery. Result for school function before surgery is quite poor (12.54) and becomes quite good (7.38) after surgery. Result for emotional function before surgery is quite good (9.69) and increases after surgery but still in quite good category (7.0) after surgery. All the results were analyzed using Npar test and Wilcoxon signed-rank test with $p<0.05$. Analysis showed significant improvement in all categories (Table 3).

\section{Discussion}

All children with brain tumor with surgical treatment without chemotherapy and radiotherapy were included in research. This research showed that 
Table 3: Analysis of PedsQL using Npar test, Wilcoxon signedrank test

\begin{tabular}{llll}
\hline Treatment & Mean \pm SD & Min/max & p value \\
\hline Quality of life & & & \\
$\quad$ Before & $58.54 \pm 11.57$ & $38 / 84$ & $0.000^{*}$ \\
$\quad$ After & $37.3 \pm 14.24$ & $16 / 66$ & \\
Physical function & & & \\
$\quad$ Before & $23.61 \pm 3.35$ & $18 / 32$ & $0.000^{*}$ \\
$\quad$ After & $15.54 \pm 5.38$ & $6 / 24$ & \\
Emotional function & & & \\
$\quad$ Before & $9.69 \pm 4.26$ & $4 / 20$ & $0.029^{*}$ \\
$\quad$ After & $7.0 \pm 6.46$ & $0 / 20$ & \\
Social function & $12.69 \pm 3.79$ & $6 / 20$ & $0.000^{*}$ \\
$\quad$ Before & $7.38 \pm 5.85$ & $0 / 20$ & \\
$\quad$ After & $12.54 \pm 3.73$ & $8 / 20$ & $0.000^{*}$ \\
School function & & & \\
$\quad$ Before & & & \\
$\quad$ After & & & \\
\hline
\end{tabular}

surgical treatment improves quality of life in all daily function significantly (Table 3). Improvement of from quite poor to quite good was found in all functions except in emotional function but still improved significantly. A study by Kim et al. showed that global quality of life and emotional function were significantly improved, but physical function was aggravated, especially for dyspnea, communication deficit, and leg weakness. Quality of life was mostly influenced by financial difficulty and future uncertainty [7]. A study by Kuhlthau et al. from 142 children (aged 2-18 years) with brain tumor and completed treatment protocol also showed similar result. Health-related quality of life from these children improves significantly after treatment at the 3 years follow-up. Physical health scores somewhat below psychosocial health score and within the score showed that the worst result was school functioning followed by emotional and social functioning scores [8].

Multicenter study from Canada using retrospective cohort study with 800 survivors of brain tumor below 18 years old compared to 923 control patients that were matched with age and gender was done to show children development outcomes and certain neurological deficit. This study showed that most common social problems to survival were learning disability and emotional problems and has no close friends especially survivors that have cranial radiation. Other deficits that found in brain tumor survivors were decrease in dexterity, hearing, speech, and cognition [9].

Another study by Macartney et al. to characterize the symptom experience and health-related quality of life from 50 children (aged 2-18) who have completed brain tumor therapy. This study showed that the most common symptoms encountered by the participants were lack of energy, pain, headache, disturbance of concentration, and sleep problem. These symptoms were independently related to decrease of quality of life [10]. Similar result was showed by Collins et al. study from 160 children (aged 10-18) with cancers. This study also resulted that the most common symptoms that related to quality of life is lack of energy, pain, nausea, loss of appetite, and psychological problems such as sadness, nervousness, worrying, and irritability [11].

Children with brain tumor that survived after surgery have to bear lifelong problem caused by neurological deficits due to tumor itself or treatment complications. These children also had substantial neurocognitive problems with serious risk for endocrine problems. Several patients need long-term support systems, i.e., rehabilitation, psychosocial support, and regular medication, not a simple assignment even in good health-care systems. The problems faced by these patients not only about medical but more about social, familial, and health-care systems [12], [13].

This study used questionnaire by phone called so the limitation was not capable to evaluated children's expression. However, expression evaluation did not influence the final result of this research. The advantage of this study is the questionnaire that used can present the quality of life through four functions.

\section{Conclusion}

Quality of life in children with brain tumor before and after surgery showed significant improvement including physical, emotional, social, and school function. Surgical intervention was not only effective in managing brain tumor but also in improving quality of life.

\section{References}

1. Crawford J. Childhood Brain Tumors. Pediatr Rev. 2013;34(2):63-77.

2. Bhat SR, Goodwin TL, Burwinkle TM, Lansdale MF, Dahl GV, Huhn SL, et al. Profile of daily life in children with brain tumors: An assessment of health-related quality of life. J Clin Oncol. 2005;23(24):5493-500. https://doi.org/10.1200/jco.2005.10.190 PMid:16110009

3. Loonen HJ, Derkx BH, Otley AR. Measuring health- related quality of life of pediatric patients. J Pediatr Gastroenterol Nutr. 2001;32(5):523-26. https://doi. org/10.1097/00005176-200105000-00006 PMid: 11429510

4. Kun LE, Mulhern RK, Crisco JJ. Quality of life in children treated for brain tumors. J Neurosurg. 1983;58:1-6. https://doi. org/10.3171/jns.1983.58.1.0001

5. Child Self-Report (CHQ-CF87). In: Michalos AC editors. Encyclopedia of Quality of Life and WellBeing Research. Dordrecht: Springer; 2014. https://doi. org/10.1007/978-94-007-0753-5_100468

6. Varni JW, Burwinkle TM, Seid M, Skarr D. The PedsQL 4.0 as a pediatric population health measure: Feasibility, reliability, and validity. Ambul Pediatr. 2003;3(6):329-41. https://doi. org/10.1367/1539-4409(2003)003<0329:tpaapp>2.0.co;2

PMid: 14616041

7. Kim CW, Joo JD, Kim YH, Han JH, Kim CY. Health-related quality of life in brain tumor patients treated with surgery: Preliminary result of a single institution. Brain Tumor Res Treat. 2016;4(2):87-93. https://doi.org/10.14791/btrt.2016.4.2.87 PMid:27867917

8. Kuhlthau KA, Pulsifer MB, Yeap BY, Rivera MD, Delahaye J, 
Hill KS, et al. Prospective study of health-related quality of life for children with brain tumors treated with proton radiotherapy. J Clin Oncol. 2012;30(17):2079-86. https://doi.org/10.1200/ jco.2011.37.0577

PMid:22565004

9. Singh O, Meena RN, Srivastava V, Pandey V, Shah AG, Meena RK. Impact of brain tumour treatment on quality of life in children: A health perspective. Neurooncol Open Access. 2016;1:1.

10. Macartney G, VanDenKerkhof E, Harrison MB, Stacey D. Symptom experience and quality of life in pediatric brain tumor survivors: A cross-sectional study. J Pain Symptom Manage. 2014;48(5):95767. https://doi.org/10.1016/j.jpainsymman.2013.12.243 PMid:24704799

11. Collins JJ, Byrnes ME, Dunkel IJ, Lapin J, Nadel T, Thaler HT, et al. The measurement of symptoms in children with cancer J Pain Symptom Manage. 2000;19(5):363-77. https://doi. org/10.1016/s0885-3924(00)00127-5

PMid: 10869877

12. Gupta P, Jalali R. Long-term survivors of childhood brain tumor: Impact on general health and quality of time. Curr Neurol Neurosci Rep. 2017;17(12):99. https://doi.org/10.1007/ s11910-017-0808-0

13. Gunn ME, Lähdesmäki T, Malila N, Arola $M$, Grönroos $M$, Matomäki $\mathrm{J}$, et al. Late morbidity in long-term survivors of childhood brain tumors: A nationwide registry-based study in Finland. Neuro Oncol. 2015;17(5):747-56. https://doi. org/10.1093/neuonc/nou321

PMid:25422316 